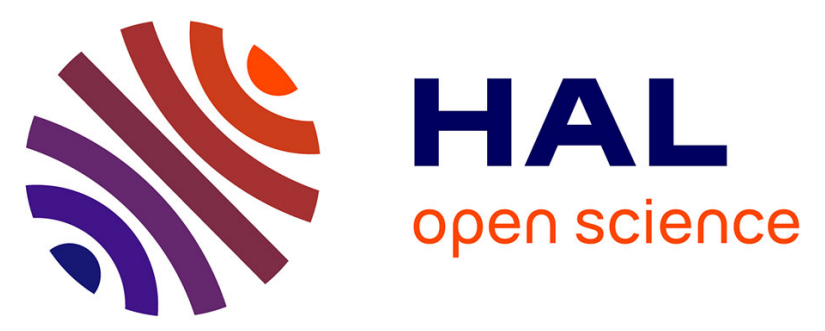

\title{
High-latitude ionospheric irregularities during the 25-26 August 2018 geomagnetic storm as seen by ground-based and space-borne instruments
}

\author{
E Astafyeva, Yu Yasyukevich, A Yasyukevich, B Maletckii, S Syrovatskii
}

\section{- To cite this version:}

E Astafyeva, Yu Yasyukevich, A Yasyukevich, B Maletckii, S Syrovatskii. High-latitude ionospheric irregularities during the 25-26 August 2018 geomagnetic storm as seen by ground-based and spaceborne instruments. Proceedings of the XXXVIth URSI General Assembly and Scientific Symposium, Mar 2021, Rome, Italy. hal-03376123

HAL Id: hal-03376123

https://hal.science/hal-03376123

Submitted on 13 Oct 2021

HAL is a multi-disciplinary open access archive for the deposit and dissemination of scientific research documents, whether they are published or not. The documents may come from teaching and research institutions in France or abroad, or from public or private research centers.
L'archive ouverte pluridisciplinaire HAL, est destinée au dépôt et à la diffusion de documents scientifiques de niveau recherche, publiés ou non, émanant des établissements d'enseignement et de recherche français ou étrangers, des laboratoires publics ou privés. 


\title{
High-latitude ionospheric irregularities during the 25-26 August 2018 geomagnetic storm as seen by ground-based and space-borne instruments
}

\author{
E. Astafyeva*(1), Yu. Yasyukevich ${ }^{(2)}$, A. Yasyukevich ${ }^{(2)}$, B. Maletckii ${ }^{(1,2)}$ and S. Syrovatskii ${ }^{(3)}$ \\ (1) Université de Paris, Institut de Physique du Globe de Paris, Paris, France, e-mail: astafyeva@ipgp.fr \\ (2) Institute of Solar-Terrestrial Physics, Siberian Branch of Russian Academy of Sciences, Irkutsk, Russian Federation
}

(3) Lomonosov Moscow State University, Moscow, Russian Federation

\begin{abstract}
In this work, we analyze the occurrence of ionospheric irregularities during the 25-26 August 2018 geomagnetic storm. With the minimum SYM-H excursion of -206 nT, this storm is the third largest in the solar cycle 24 . It produced strong effects in the ionosphere, especially in the American and Pacific longitudinal sectors. Here we use a combination of ground-based (GNSS) and spaceborne (Swarm and CSES) instruments in order to detect the occurrence of intensive ionospheric irregularities. We show that the most significant impact was done at highlatitudes. In the North American region, the area with irregularities descended to $42-45 \mathrm{~N}$. The location of the observed irregularities corresponded, most likely, to the auroral oval region. The use of satellite measurements added more information on the spatial distribution of the irregularities, which is especially important in areas with limited coverage by ground-based GNSS stations.
\end{abstract}

\section{Introduction}

Geomagnetic storms are known to generate significant disturbances in the ionosphere. They are also known to be a major source of ionospheric irregularities of different scales [e.g., 1, 2]. Such irregular structures in the ionosphere can cause scintillations of radio-signals, and can even lead to radio blackouts. Therefore, knowing the areas of their occurrence is crucially important.

In this work, we analyze the occurrence of irregularities of the ionospheric electron density and total electron content (TEC) during geomagnetic storm of 25-26 August 2018. The storm caused significant response in the ionosphere and thermosphere, especially in the American and Pacific longitudinal sectors [e.g., 3].

\section{Data set \& Method}

To detect the areas with significant ionospheric irregularities during the 25-26 August 2018 storm, we estimate the following parameters:

1) Density of TEC Slips in data of ground-based GNSSreceivers. This parameter was calculated as previously suggested as a number of sudden TEC jumps with respect to the total number of observations [2]. The value of TEC change over an epoch that be considered as a TEC slip, depends on latitudes. Here, the following jumps in the slant TEC were regarded as TEC slips: 3 TECU per $30 \mathrm{~s}$ interval for low latitudes, 2 TECU/30 s for mid-latitudes (between $\pm 25^{\circ}$ and $\pm 75^{\circ}$ Lat) and 1TECU/30s for high latitudes (over $\pm 75^{\circ}$ of Lat). We note that such estimations were done separately for GPS and Glonass observations.

2) Rate-of-TEC Index (ROTI) was calculated for the measurements of ground-based GNSS receivers located worldwide. The ROTI is an index characterizing the intensity of small-scale irregularities [4]; it is calculated as a root-mean-square of the rate of TEC (ROT):

$$
R O T I=\sqrt{<R O T^{2}>-<R O T>^{2}}
$$

where $R O T=\Delta I / \Delta t, \Delta I$ is the TEC change over time $\Delta t$, i.e. a temporal resolution of measurements (typically 30 $\mathrm{s})$. The ROTI is calculated over the 5-min time interval [5]. Similar method was applied to the Swarm TEC data, in order to calculate the ROTI for the topside TEC measurements performed by the GPS-receiver onboard Swarm satellites. The ROTI was calculated with $10 \mathrm{~s}$ running window [6].

3) Rate-of-Density Index (RODI) was calculated based on space-borne in-situ measurements of the electron density (Ne) performed by Langmuir Probes onboard Swarm [7] and the China Seismo Electromagnetic Satellite (CSES) [8] satellites. First, rate-of-Density (ROD) was calculated for consecutive epochs similar to ROT. Second, RODI is calculated as the standard deviation of ROD values in a centered running window of $\Delta t$, i.e. only ROD values calculated between $(\mathrm{t}-\Delta t / 2)$ and $(t+\Delta t / 2)$ are taken into account. Then, RODI at each definite time $t$ is:

$R O D I(t)=\sqrt{\frac{1}{N-1} \sum_{t_{i}=t-\frac{\Delta t}{2}}^{t+\frac{\Delta t}{2}}\left|R O D\left(t_{i}\right)-\overline{R O D}(t)\right|^{2}}$

$R O D\left(t_{i}\right)$ are ROD values falling inside the window centered at time $\mathrm{t}$ and $\Delta \mathrm{t}=30 \mathrm{~s}$ wide for the CSES 
Langmuir Probe data [9] and $10 \mathrm{~s}$ and $20 \mathrm{~s}$ wide for the Swarm Langmuir Probe data [6]. N is the number of ROD values, while $\overline{R O D}(t)$ is the mean of ROD values in the window.

As known, the Swarm constellation consists of three identical satellites: (A)lpha, (B)ravo and (C)harlie. Swarm $A$ and $\mathrm{C}$ spacecrafts fly only several minutes and several degrees of longitudes apart and, in most cases, show quite similar measurements. Here we only use data from A and B (denoted below as SWA and SWB, respectively). The orbital altitudes of the satellites are the following: 430$460 \mathrm{~km}$ for SWA, $498-525 \mathrm{~km}$ for SWB and 507-524 km for CSES. The spacecrafts performed measurements in $2.4 \& 14.4 \mathrm{LT}$ (SWA), $9.6 \& 21.6 \mathrm{LT}$ (SWB) and $\sim 2 \&$ $\sim 14 \mathrm{LT}$ sector (CSES).

4) Precise point positioning (PPP) coordinates in kinematic mode were calculated for every GPS station, globally. For this purpose, we used the "GAMP" open source software [Zhou et al., 2018]. Receiver and satellite clock offsets were considered in GAMP PPP solution by applying IGS precise satellite orbit and clock products. The 24-hour averaged values of X, Y, Z coordinates for a station were regarded as reference positions. The total positioning error was calculated as a difference between

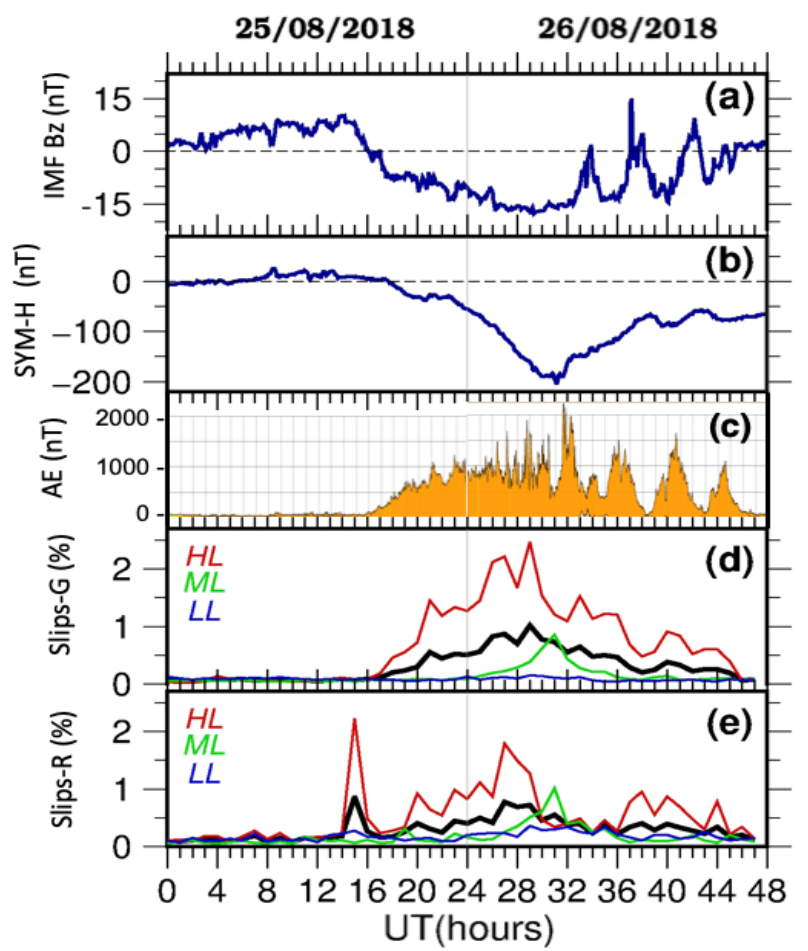

Figure 1. Variations of the Interplanetary magnetic field (IMF) Bz component (a), the SYM-H index (b) and the AE-index (c). Panels (d) and (e) show the percentage of TEC slips for GPS and Glonass satellites, respectively. The solid black curves show the global value, red - the TEC-slips at high latitudes, green - at middle latitudes and blue - at low-latitudes. The IMF-Bz and SYM-H data are 5-min cadence, and the TEC Slips data are 1-hr cadence. the reference and the instant position:

$$
\sigma_{X Y Z}=\sqrt{\left(\Delta X^{2}+\Delta Y^{2}+\Delta Z^{2}\right)}
$$

\section{The August 2018 storm and its effects on the GNSS performance}

Figure 1 shows variations of interplanetary and geophysical parameters during the 25-26 August 2018 geomagnetic storm. The storm was triggered by the interplanetary coronal mass ejection (ICME) that arrived at Earth at $\sim 2: 45 U T$ on 25 August 2018. The ICME arrival did not cause a sudden geomagnetic impulse, and no sudden storm commencement can be seen in SYM-H data (Figure 1b). The interplanetary magnetic field (IMF) $\mathrm{Bz}$ component turned southward at 17UT and caused an intense geomagnetic storm that lasted for $\sim 10$ hours (Figure 1a). The minimum SYM-H values reached -206 nT at $\sim 7$ UT on 26 August 2018. Starting from 7UT, the SYM-H started to increase and reached the undisturbed 0
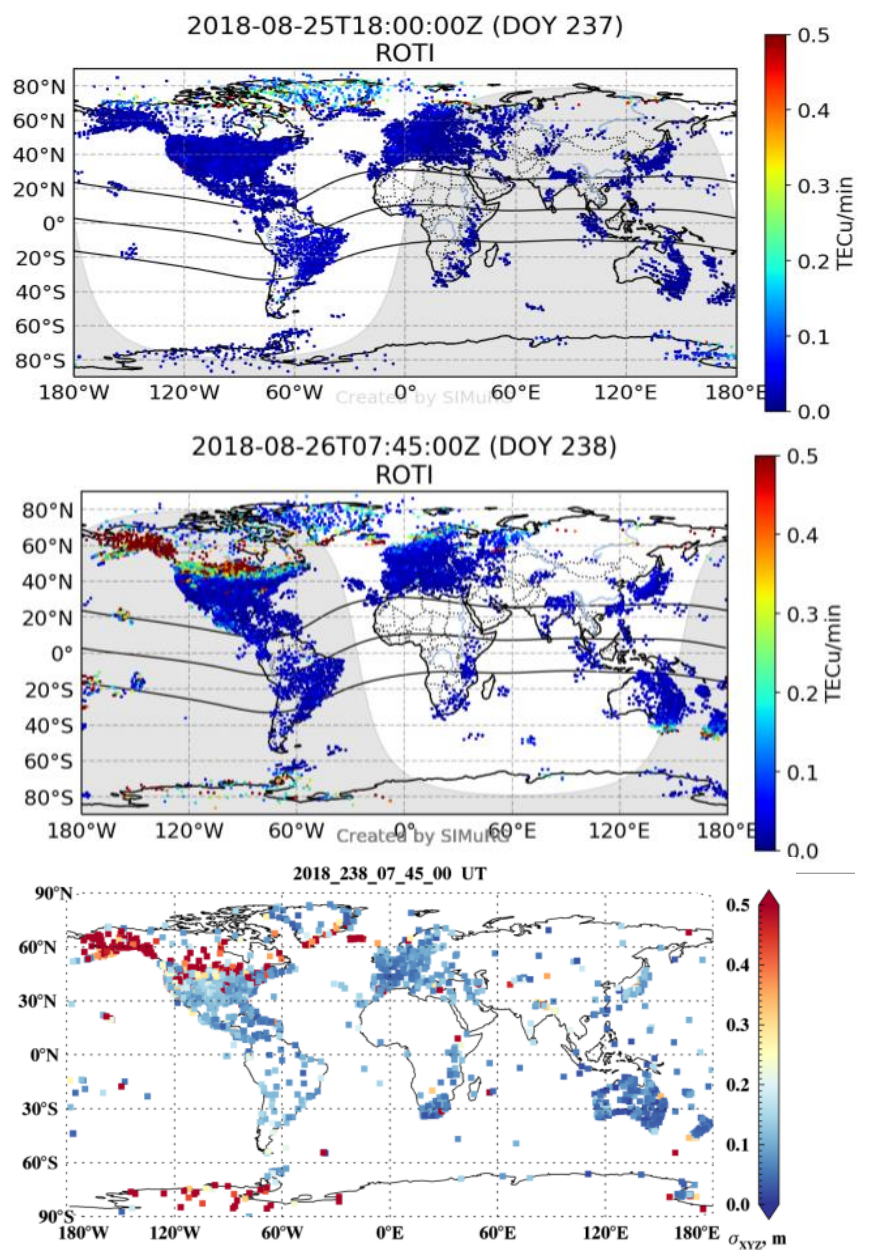

Figure 2. Global maps of ROTI at the beginning of the storm at 18UT on 25 August (top) and at the beginning of the recovery phase of the storm at 7:45UT on 26 August 2018 (middle). The Maps are created by the SIMURG online service (http://simurg.iszf.irk.ru). (bottom) distribution of PPP errors (in m) at 7:45 UT on 26 August 2018. 
nT on 27 August. The storm was also characterized by enhance auroral activity, especially at the beginning of the recovery phase, when the AE index exceeded $2000 \mathrm{nT}$ (Figure 1c).

Such a strong geomagnetic disturbance caused significant effects in the ionosphere and thermosphere [e.g., 3].

\section{6/08/2018 07:20 UT}
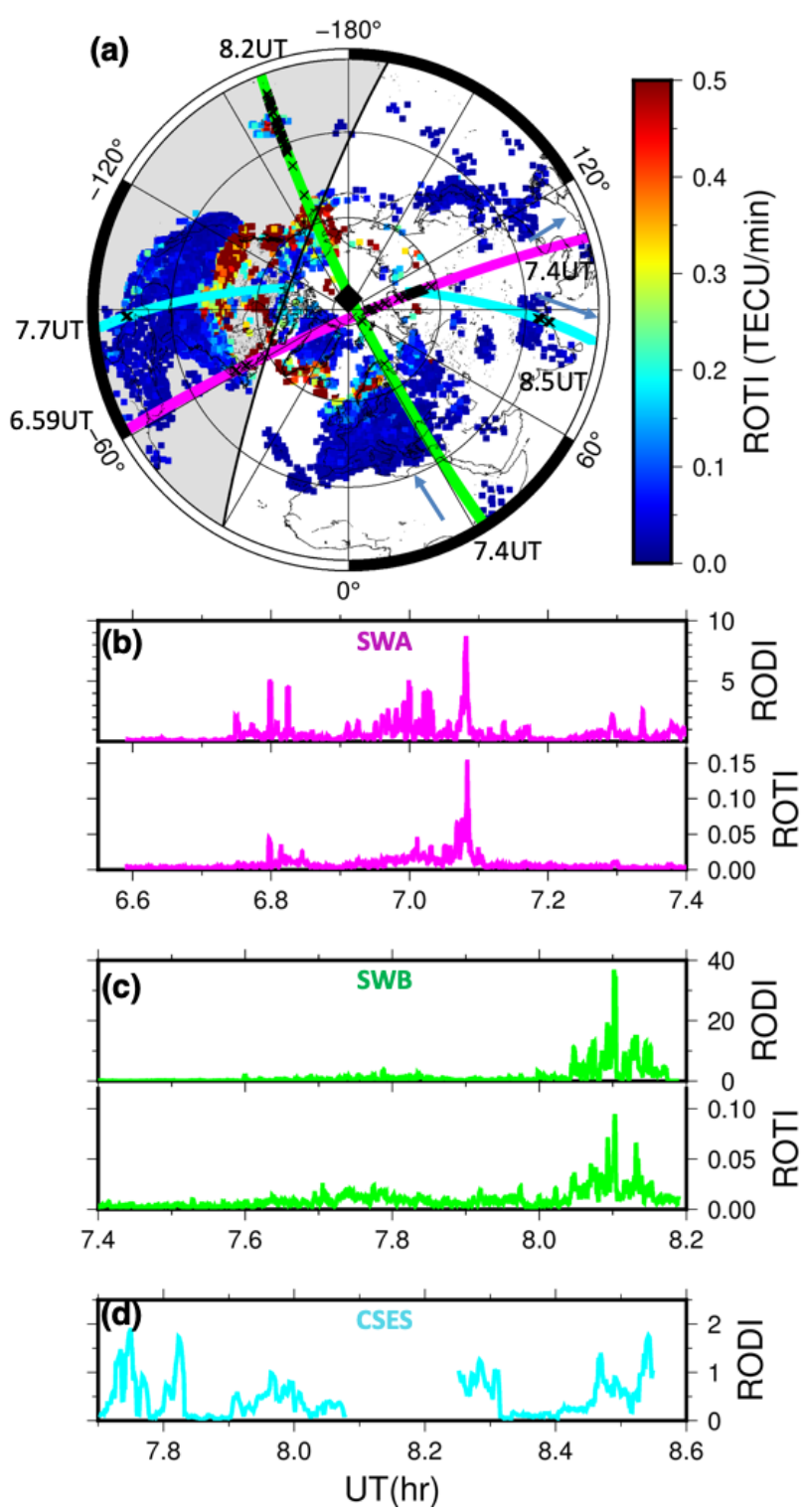

Figure 3. Dynamics of ionospheric disturbances over Northern Hemisphere: (a) ROTI as calculated from measurements of ground-based GNSS-receivers at 7:20UT on 26 August 2018. Green, magenta and Brown curves show the positions of SWA, SWB and CSES spacecrafts. Black crosses on the orbital passes indicate the areas with high RODI/ROTI; (b, c) - Electron density (Ne), RODI and ROTI from SWA (b), and SWB (c); (d) - RODI as calculated from the in-situ $\mathrm{Ne}$ measurements by CSES. The Arrows on panel (a) indicate the direction of spacecraft motion, the times of the passes are indicated next to the tracks. Black crosses show the "perturbed areas" based on levels of RODI and ROTI. RODI values are in $* 1 \mathrm{e} 3 \mathrm{~cm}^{-3}$ units.
Specifically, a very pronounced hemispheric asymmetry was observed in the thermospheric neutral mass density and in the $\mathrm{O} / \mathrm{N} 2$ composition ratio. In the ionosphere, a very strong positive ionospheric storm was observed during the main phase and beginning of the recovery phase of the storm in the Northern Hemisphere $(\mathrm{NH})$ in the American sector. In the Southern Hemisphere ( $\mathrm{SH})$, no signs of positive ionospheric storm effect were observed.

The global values of TEC-slips for GPS (G) and Glonass (R) observations are shown in Figure $1 \mathrm{~d}$ and 1e, respectively (black lines). The dynamics of G-TEC-slips follows the development of the storm: it starts to increase with the beginning of the storm at $\sim 17 \mathrm{UT}$, it reaches the maximum value of $1 \%$ by 5-6UT on 26 August, and descends to undisturbed value at the end of the day. The TEC-slips in Glonass observations reached $0.8 \%$ during the storm, and one can observe a spike of $\sim 2.2 \%$ before the storm. The latter is, most likely, related to very few high-latitude observation points in Glonass measurements.

Further separation into latitudinal sectors shows that the vast majority of slips occurs at high-latitudes. In G-TECslips, the value reaches $3.4 \%$, while in R-TEC-slips the maximum value is $\sim 1.8 \%$. The TEC-slips at mid-latitudes reach $1 \%$ at $6-7 \mathrm{UT}$ on 26 August. The latter is, most likely, caused by the descend of the ionospheric disturbances from high-latitudes into mid-latitudes. Indeed, Figure 2 shows that in American sector, in Northern Hemisphere the area of high ROTI values, and, therefore, that of intensive ionospheric perturbations, shifted from $\sim 70-80 \mathrm{~N}$ at $18 \mathrm{UT}$ to $\sim 40-50 \mathrm{~N}$ at $07: 45 \mathrm{UT}$. One can observe some increase of the TEC fluctuations over Eurasia as well. We note that the ROTI-disturbance correspond to the area with high PPP errors (Figure 2).

During this time, the southern hemisphere seems to be much less perturbed. This might be partly caused by small number of GNSS-receivers in Antarctica. Figures 3a and $4 \mathrm{a}$ show the ROTI values over the Northern and Southern hemispheres, respectively. The maps correspond to the period of time of the maximum TEC slips: at 7:20UT $(\mathrm{NH})$ and at 6:45UT $(\mathrm{SH})$. Over the $\mathrm{NH}$, one can see a large area of high ROTI values along 60-70N. Over North America, and during the local night hours, the area extended to $42-45 \mathrm{~N}$, which might be caused by the descend of the auroral oval. Further work is needed to verify this presumption. In the $\mathrm{SH}$, we observe 2 small areas of enhanced ROTI-values: one in the polar region in the American sector, and another is at middle latitudes in the Pacific Ocean (Figure 4a). The SH seems much less affected than the NH polar and auroral regions. However, unfortunately, due to very sparse GNSS-coverage we are unable to obtain more details for the SH. Therefore, in order to further investigate the dynamics of the irregularities over high-latitudes, we further analyze space-borne data from Swarm and CSES missions. One can see that over the NH the areas of high ROTI and 
RODI coincide with the "perturbed" areas detected by ground-based GNSS. Over SH, with very sparse GNSScoverage, the satellite data provide additional information about the spatial distribution of ionospheric irregularities.

\section{6/08/2018 06:45 UT}
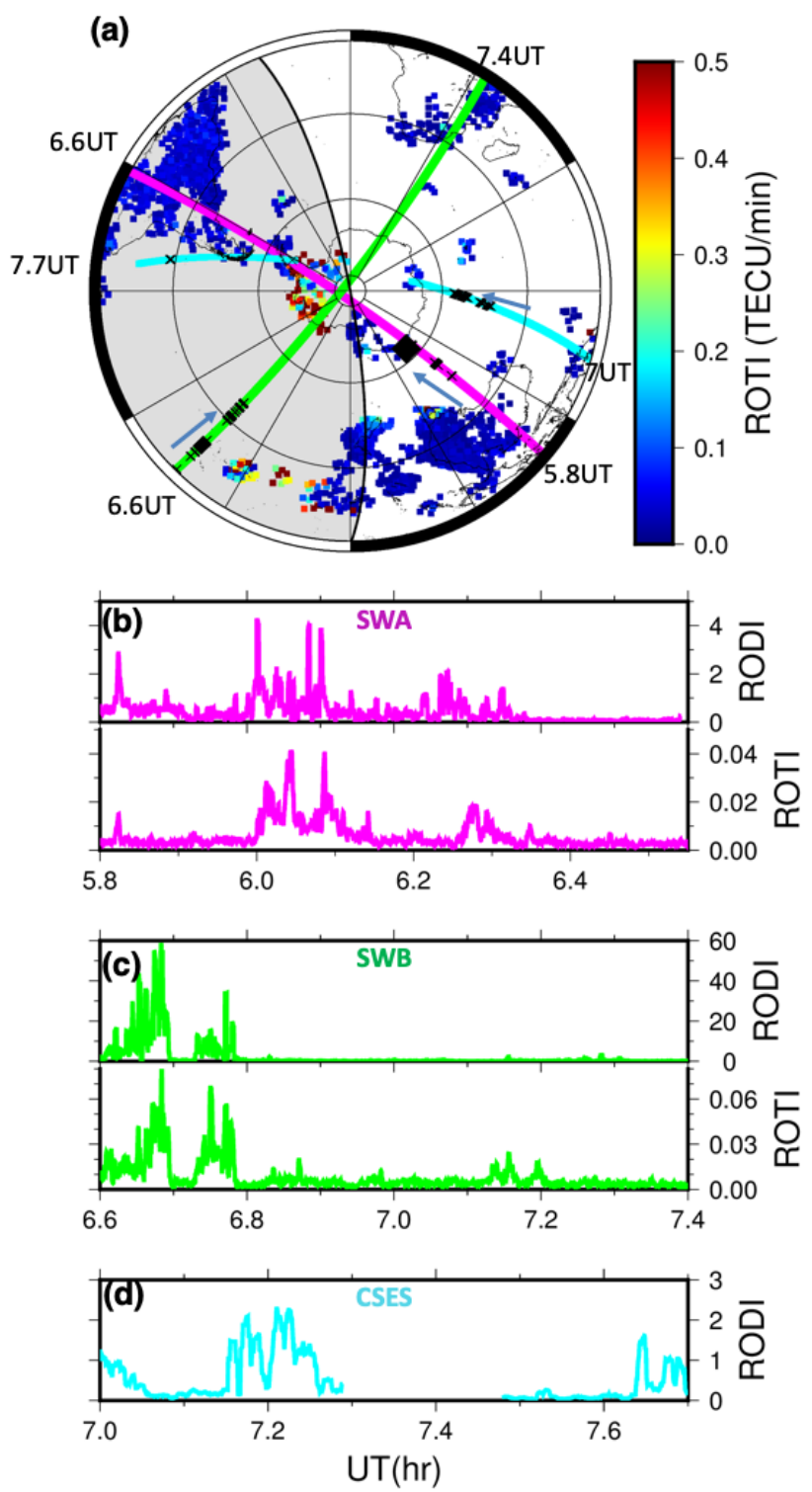

Figure 4. Same as Figure 3 but for the Southern Hemisphere and earlier time: (a) - ROTI at 06:45UT, (b) - SWA at 5.8-6.58UT, (c) - SWB at 6.6-7.4UT, (d) - CSES at 7.0-7.7UT.

\section{Acknowledgements}

EA acknowledges the support of the French Space Agency (CNES) for the support. YY and YA thank the support of the RFBR and the Government of the Irkutsk Region under the project 20-45-383010 and the budgetary funding of the Basic Research Program II.16. BM thanks the CNES for the PhD fellowship. We acknowledge the NASA/GSFC's Space Physics Data Facility's OMNIWeb service for the data of the interplanetary and geophysical parameters and the World Data Center for Geomagnetism in Kyoto (WDC-Kyoto, http://wdc.kugi.kyoto-u.ac.jp/) for the data of the AE index. The ROTI maps are available from the SIMURG web-service (http://simurg.iszf.irk.ru). We thank the European Space Agency for the Swarm data (http://earth.esa.int/swarm) and the Center for Satellite Application in earthquake Science for the CSES mission data (http://www.leos.ac.cn/). The Figures are done by using the GMT6.0 software [11].

\section{References}

1. Afraimovich, E.L. et al., "Geomagnetic storms and the occurrence of phase slips in the reception of GPS signals", Ann. Geophys., 2002, 45 (1), pp. 55-71.

2. Astafyeva, E., et al. "Geomagnetic storms, superstorms and their impact on GPS-based navigation". Space Weather, 2014, 12, 508-525, doi:10.1002/2014SW001072

3. Astafyeva, E., M.S. Bagiya, M. Förster, N. Nishitani. "Unprecedented hemispheric asymmetries during a surprise ionospheric storm: a game of drivers". $J$. Geophys. Res., 2020, 125 (3,) doi:10.1029/2019JA02726

4. Pi X, Mannucci AJ, Lindqwister UJ, Ho CM. Monitoring of global ionospheric irregularities using the worldwide GPS network. Geophys Res Lett., 1997, 24(18):2283-2286. doi:10.1029/97GL02273

5. Yasyukevich, Y.V., et al. SIMuRG: System for Ionosphere Monitoring and Research from GNSS. GPS Solutions, 2020, 24, 69 .

6. Jin, Y., et al. "Ionospheric Plasma Irregularities Characterized by the warm Satellites: Statistics at High Latitudes". J. Geophys. Res., 2019, 124, pp. 1262-1282.

7. Buchert, S., et al., "SWARM observations of equatorial electron densities and topside GPS track losses", Geophys. Res. Lett., 2015, 42, pp. 2088-2092.

8. Shen, X., et al, "Introduction to special section on the China Seismo-Electromagnetic Satellite and initial results". Earth Planetary Phys., 2018, 2, 439.

9. Piersanti, M. et al. "From the Sun to the Earth: August 25, 2018 geomagnetic storm effects", Ann. Geophys., 2020, doi: 10.5194/angeo-2019-165.

10. F. Zhou, et al., "GAMP: An open-source software of multi-GNSS precise point positioning using undifferenced and uncombined observations," GPS Solutions, 2018, 22(33), doi:10.1007/s10291-018-0699-9.

11. Wessel, P., et al. "The Generic Mapping Tools Version 6". Geochemistry, Geophysics, Geosystems, 2019, 20 (11), doi: 10.1029/2019GC008515 